\title{
AVALIAÇÃO DOS MÉTODOS DE ESTUDO DOS DISCENTES
}

\section{Ryan Luiz da Silva Oliveira ${ }^{1}$ \\ Israel Cardoso ${ }^{2}$}

Resumo: Este trabalho apresenta o resultado de uma pesquisa estatística realizada com 113 discentes oriundos de instituições de ensino públicas e privadas, com o objetivo de investigar os métodos e o tempo dedicado aos estudos. Onde $69 \%$ dos discentes estuda há um período de até dois anos em sua atual instituição de ensino. Do total de discentes, 46,9\% dedicam de uma a três horas de seu dia para estudar, e desse total, $83,2 \%$ preferem estudar individualmente, devido a um melhor rendimento pessoal. Desses discentes, $69,9 \%$ se consideram iguais a seus demais colegas de classe, e que 13,3\% são os que consideram estudar mais que seus colegas. Essa pesquisa traz o resultado de outras duas pesquisas, sendo uma do Instituto de Pesquisa Econômica Aplicada (Ipea) e outra da Universidade Federal do Ceará (UFC), cujos resultados obtidos na avaliação dos métodos de estudo dos discentes, quando analisados com essas pesquisas, nos mostram que ambas apresentam resultados parecidos.

Palavras-chave: Avaliação discente; Hábitos de estudos; Tempo de estudo.

1 Instituto Federal do Espírito Santo/IFES - Campus Cachoeiro de Itapemirim, Brasil. E-mail: ryanluiz2006@hotmail.com.

2 Instituto Federal do Espírito Santo/IFES - Campus Cachoeiro de Itapemirim, Brasil. E-mail: israelc@ifes.edu.br. 